\title{
12
}

\section{Value(s) Creation}

Thuisafgehaald - a home cooking peer-to-peer meal service-is in business with the aim of creating a better world. Our social goal comes first, but we apply business principles in our approach. We define profit in broader terms than just financially. Our profit consists of the social and sustainable added value that we offer to society. Thuisafgehaald, www.thuisafgehaald.nl.

Granny's Finest is a slow fashion label that contributes to the social participation of senior citizens. With all our products being handmade from natural, reused, and certified materials, we work on greater social cohesion, preservation of craftsmanship, and a sustainable world. This makes you feel good. Granny's Finest, www.grannysfinest.com.

We at Gasunie are in the business of extracting and distributing natural gas. For each of the six forms of capital (financial, manufactured, intellectual, human, social \& relational, and natural), our value creation model shows how we use these to achieve our strategic objectives. It also visualizes the values we create through our core activities and what impact these have. Gasunie, www. gasunie.nl.

Next to taking care of people and the environment in the countries of origin, we also take a critical look at our packaging, the production process, waste, and transport. By working closely with the producers, we not only improve our coffee and tea but also the living and working conditions of the workers. Simon Levelt, www.simonlevelt.nl.

Taxi Electric is actively recruiting drivers among [...] people over 50. We offer any service-oriented and friendly driver a chance to come and work for us. Never before has nature faced such hard times. Therefore, we drive solely 
electrical vehicles charged with green electricity. That is our contribution to a healthy city. Taxi Electric, www.taxielectric.nl.

De Nederlandsche Bank [the Dutch National Bank] states that the financial sector is also confronted with social and environmental risks. The sector can play a key role in working with true value and true pricing: monetizing external costs and being aware of multiple value creation. This not only concerns financial developments and results but also ecological and social effects. National Network MVO (Corporate Social Responsibility-CSR), The Netherlands, www.mvonederland.nl.

The three pillars (People First, Living our Values, and Develop for the Future) reinforce the most relevant topics for our people: (1) an environment in which everyone can grow, perform and succeed, (2) an environment where people feel they belong and have their voices heard, (3) an environment where people can develop themselves to be fit for the future. Ultimately, we want to create a fulfilling employee experience and become an employer of choice. Arcadis, www.arcadis.com .

\subsection{Everything Is a Transaction and Has Value}

With this chapter, we have arrived at what we consider to be the most challenging building block of the BMT, Building Block \#10-Value Creation. A business model provides a logic for value creation (see Chapter 2) that is translated into a proposition (see Chapter 5). Transactions in turn are the operational acts that demonstrate an appreciation of the value created between parties, while also realizing it. For this reason, they are also considered the actual moment to settle within a value creation process.

A key assumption is that you normally pay for what you buy. Consequently, we can say from this perspective that our society is designed based on an endless flow of transactions-large and small, day in and day outwhich we usually complete financially. However, while not mainstream yet, in addition to financial settling, other forms of settling may be more appropriate under certain circumstances depending on the nature of the value(s) being created.

Here we make an explicit distinction between the value bearer and the transaction medium, for example, money and the transaction itself. Money is a unit of account, a medium of exchange, or a store of value. In contrast, 
a transaction is an action between parties. ${ }^{1}$ In the dominant prevailing economic context, a transaction translates as a payment in cash or the receipt of money.

We construct our existence with transactions. We do this constantly, consciously and unconsciously, sometimes with lots of meaning but at times inconspicuously, and also over varying time spans (long- and short-term). Transactions are translated into daily activities, such as buying a loaf of bread, paying for a haircut, a car, a house or the electricity and water you use at home. Those transaction processes continue throughout our day-often just between two parties, sometimes with multiple parties.

All this leads to a dynamic mix of transactions between people (C2C), between people and governments (C2G and $\mathrm{G} 2 \mathrm{C})$, between people and companies ( $\mathrm{C} 2 \mathrm{~B}$ and $\mathrm{B} 2 \mathrm{C})$, between companies themselves (B2B), between companies and governments (B2G and G2B), and between governments (G2G). We call this economy. So, there are transactions in all shapes and sizes, with large and small impacts. Because it is not always clear what the transactions are and how these can be used in the context of sustainable business models, it makes sense to rank them in order. Therefore, in this chapter we present a typology of transactions and related PSS strategies, which in turn we link to the concept of multiple (hybrid) values (e.g. sales, take-back, deposit, rent and use). What we want to explain as clearly and as unambiguously as possible is how multiple value(s) creation can be achieved within and through a broad variety of transactions.

\subsection{Speaking of Transactions}

Anyone who thinks superficially about the word transaction, certainly in an organizational or business environment, quickly interprets that concept as an agreement in which goods, whether or not in combination with services, are exchanged based on monetary valuation (in mutual comparison). This exchange contains both a valuation and, often, a change in ownership. This turns transactions into the operational acts that demonstrate an appreciation of the value created between parties, while also realizing it. As outlined earlier, this can be done bilaterally between two parties, or multilaterally between several parties.

\footnotetext{
${ }^{1}$ It is worth noting that there are many other meanings attributed to the word transactions, for example law (notably criminal law), IT, trade, and sociology, which go beyond the scope of the BMT and therefore we will not expand on here.
} 
For transactions to run smoothly and efficiently, we need to regulate and organize them together. Based on a long history, a dominant monetized transaction system has come to exist. We express our appreciation of a good or service through a sum of money. A transaction is the exchange mechanism that regulates the valuation of a good or service between parties. In other words, it is the sum that changes hands in exchange for a product or service. It also means that we pay for what we want to have but also to meet the demand of the other party. After all, we buy a loaf of bread (after which we own it), but we also purchase the services of the hairdresser, after which we own a haircut. These are of value because we can satisfy our appetite or look better. Transactions are the foundation of revenue models, regardless of the nature of those transactions. However, the transaction does not reveal the value exchange (or its nature) itself, nor whether the exchange is just and correct. This raises the question of whether everything can or should be expressed in monetary terms.

\section{Transactions and Externalities}

The common implicit logic of business models leads to a valuation of transactions that is monetized, which almost automatically leads to revenue models. By doing that, we express what we find of value in money. This is certainly practical, but at the same time, it means that values that are excluded from the revenue model do not count and thus actually disappear. Monetizing only partially expresses appreciation. There remains a part that is not or is insufficiently valued, or does not need to be valued. This phenomenon is known as an externality or externalizing. An externality is any form of value (or loss of value) that is disregarded in financial transactions and therefore does not count (see, for example, Buchanan \& Stubblebine, 1962). Many unsustainable business models are based on externalizing costs. This means that underpayment of labour or the destruction or pollution of nature is not included in the (final) price. So, we have an economy based on partial pricing. We do not pay what a product or service really costs at the checkout. But someone, or, eventually, nature has to pay that price in the end. Solutions such as true pricing (see www.trueprice.org) try to do something about this.

\section{Inclusivity and Hybridization}

The almost fully automatic monetization of transactions in society leads to social and economic exclusion. After all, people who do not have access to 
money cannot participate in economic transactions - they are excluded from the system. We believe that inclusivity can be enabled by developing business models and subsequently transactions whereby multiple kinds of value(s) are exchanged simultaneously-not just financial ones. We call this hybridization of transactions and thus of revenue models. However, the possibilities of arriving at a different settlement in a transaction, let alone a settlement based on more than one value, are limited in the current institutional context. Despite these institutional blocks, other settlements are not inconceivable. Many alternatives are possible... why not pay with a mix of money and time, car use and cooking skills? These hybrid transactions enable participants to deploy multiple transaction mediums simultaneously. Consider, for example, the exchange of time, energy, mobility, care, food, or even accommodation.

Thinking in terms of financial transaction instruments is insufficient if we are to address environmental and social externalities. Alternative, more comprehensive systems are needed, for example hybrid transaction systems, in which different transaction mediums can be used both simultaneously and in combination without prior monetization. Such a system makes it possible to trade with multiple values now and in the future. Moreover, a hybrid transaction system could enable participation in society for a large group of people who currently operate on the periphery.

A hybrid system promotes, among other things, a local, direct and participatory form of economy, and thus fosters inclusivity. It also makes it possible to deploy and utilize competencies and overcapacity. In the context of the BMT, this means that you have the opportunity to design your business model underpinned by hybrid transactions. Not everything needs to be expressed as money in revenue models and transactions. But what does that mean in practice? Next we will present this idea as a typology of transactions and revenue models.

\subsection{Typology of Transactions and Revenue Models}

Business and revenue models are often spoken of as if they mean the same thing, which is not the case. As discussed in Chapter 2, business models describe how an organization or a community creates value and for whom. Revenue models on the other hand are part of value creation and show for whom it is generating values. In this book we focus on the generated multiple values, which may be hybrid in nature. We make a distinction between traditional (monetized and thus single-value) revenue models and new revenue 
models generating multiple values simultaneously. Traditional revenue models only address monetary turnover, and refer to turnover and margin based on financial transactions. Traditional revenue models offer the opportunity to work smarter and more efficiently to reduce costs or to increase the market share and, consequently, the turnover.

The most conventional form of financial transactions involves either buying a product or renting a service (temporarily). When purchasing a product, the transfer of ownership is central. Think, for example, of buying a meal, a bike, or a toaster. In contrast, renting the provision of a service is central. For a certain fee, you can use a service for a pre-agreed period of time, and ownership remains with the lessor. Examples are renting a holiday home, power tools for the garden, or a lane at a bowling alley. Tukker (2004) has arranged these traditional transactions in his overview of product-service systems - see our discussion of platform business models in Chapter 6Business Model Archetypes. In Tukkers' (2004) model a key difference is how ownership of products is organized. In product-oriented business models, the transfer of ownership is central to the transactions. Use-oriented business models, on the other hand, are based on the principle of lease and rent whereby the revenue is linked to a payment for a certain period of use. Finally, in result-oriented business models, the ownership of the product stays with the party that makes functionality available, with earnings linked to a unit of use.

In addition to these conventional revenue models, we believe that other new revenue models can underpin the business models developed by using the BMT. We distinguish two new revenue models: (1) cascade models and (2) hybrid models.

The first group of revenue models concerns cascade models. The essence of these models is that the value(s) are stacked in a loop. The various parties in this loop make mutual agreements as to how they distribute cumulative value creation among themselves.

Then there is a group of revenue models in which the transaction medium(s) are hybrid. In such revenue models, the link with money is abandoned as much as possible-and, if possible, completely. This means that you can pay with more than just money (simultaneously and in combination), or within a specific community you could agree to stop paying with money at all. This variation would offer several tax benefits, one of which being that transactions which do not involve money cannot be taxed. Either way, these different revenue models together form the basis for a typology, of which the basic structure is shown in Fig. 12.1. 


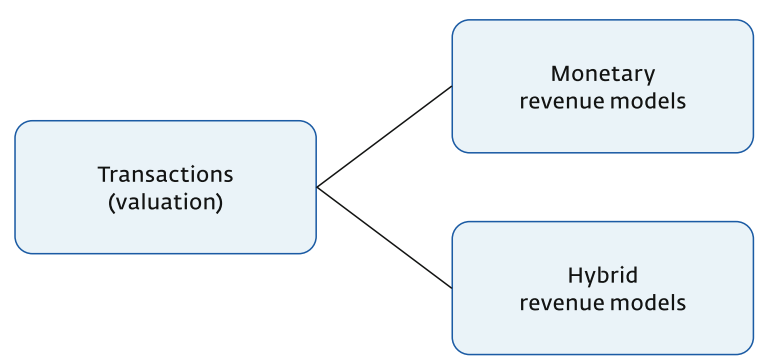

Fig. 12.1 Revenue model typology

\section{To Have or Not to Have, That is the Question}

The basis for further elaboration of a typology of business models is actually fairly simple: to have or not to have. In concrete terms, this means that a transaction can either involve ownership transfer or focus on the use of a function of a device or installation. So, you buy a car (and then it is yours with all rights and obligations), or you lease a car (where you also have rights and obligations but not the ownership). This distinction divides monetary transactions and (non-monetary) hybrid transactions.

Conventional revenue models show how monetary revenue is generated. In turn, monetary transactions show a wide range of types of revenue models. The oldest known model involves the transfer of ownership. When such a transaction generates more or another type of turnover (which is possible with a cascade model because more monetary transactions are added to one product), it is also possible to speak of a new revenue model.

Here we present an illustrative summary:

- Sale of product, part, or raw material; transfer of ownership

- Transfer of ownership (sales) of equipment for a specified period (with a buy-back guarantee)

- Sale of a product with a buy-back (or take-back) guarantee); temporary transfer of ownership

- Sales of product and related services (maintenance, advice, insurance, repair, training); transfer of ownership with rental component

- Transfer of ownership of equipment for a specific period with related service

- Sales of a total solution including service; transfer of ownership with a rental component. 
Hybrid transactions show how transactions take place based on nonmonetized transaction mediums. Hybrid transactions, therefore, do not necessarily embed a monetary revenue model, although this is possible. This leads to a preliminary (and undoubtedly incomplete) overview in which selling of the function is central, and the producer retains ownership.

Below we mention a few out of a whole range of business models based on PAAS:

- Sale of use, access to a product or function; rent per period, per performance

- Sale of performance or function of the product; rent per function of the unit

- Sale of an (integral) device

- Use by means of a deposit or security; rent per product

- Cascade model: stacking of earnings, mixed or otherwise

- Exchange based on hybrid values; simultaneous use of multiple transaction instruments.

Combining the nature of different transactions with the possibilities of using products, services, or a combination of both in a business model creates a rich spectrum of both monetary and hybrid transaction models. We have attempted to express this visually in Fig. 12.2.

The last section in this overview also gives an impulse to characterize the nature of the value. We propose a five-way division that ranges from the traditional zero-value (the usual depreciation model), through residual value (the ambition of the circular economy), through deposit (which is actually a

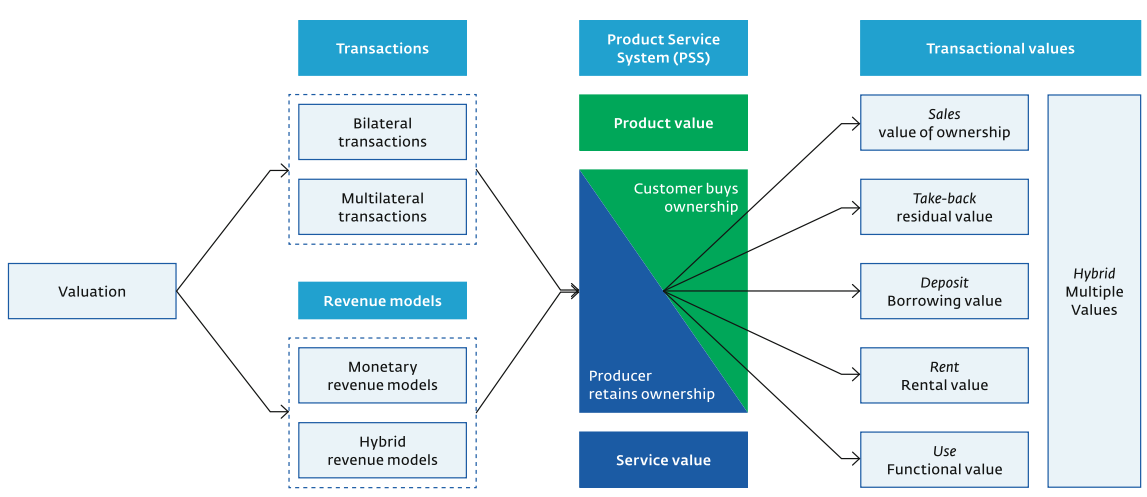

Fig. 12.2 Typology of the link between transactions, service, and multiple values 
form of loan value) to functional value (the core of PAAS), and ultimately to multiple values in the context of hybrid transactions.

\subsection{Bartering, Time Banks, and Hybrid Transactions}

Experimenting with non-monetary transactions does not come automatically or naturally as we are so used to monetary transactions. That said, people do enter into transactions (assigning value to items or services) with each other without using money. Moreover, when we reflect critically on our daily lives, there are many things that we hardly use, or maybe no longer use at all which we would be willing to give or share with others without necessarily always receiving something in return. A car that sits parked in front of the house unused, a great bike that sits unused in a shed, or having surplus food and no fridge/freezer space, or what about being able to use someone else's garden for an occasional afternoon if you do not have a garden yourself? This list is endless. However, it does require that you know who wants what, what is available, and vice versa.

We already engage in these forms of hybrid transactions organically through our families and close social networks. And therein lies the rubgiven the developments of the IoT, the IoS, the exponential growth of apps, and, last but not least, developments around the use of algorithms, systemizing hybrid transactions beyond our social networks is becoming increasingly possible.

\section{Bartering and Beyond}

Exchanging goods or bartering is not new. People have been exchanging goods for other goods for centuries, long before money was invented. It is a form of deal-making, but a key disadvantage is that such bartering can only occur between directly involved parties, and trusting who you are trading with is key. For instance, you have a bike that someone else wants to use for an afternoon, and, in return, they take a look at the website you want to buildyou are likely to want your bike returned, and sound advice regarding how to build your website to be satisfied with the deal, making trust important.

A slightly more abstract concept of bartering are so-called time banks. Here, after someone has worked for an hour, they choose to get paid in hours that are deposited in their account which they can then use to pay someone else in hours. In this case, everybody's time is valued equally and the transaction 
unit is one hour which can be traded for different services or things- see www.timebanking.org/what-is-timebanking or https://ssir.org/articles/entry/ the_time_bank_solution.

The notion of a community currency resembles the time-bank concept. These community currencies are at the heart of so-called Local Exchange Trading Systems (LETS). These types of transaction systems are also referred to as complementary currencies. Meanwhile, there are several of them in use. Examples are the WIR Bank in Switzerland, founded in 1934 (www.wir.ch), the Noppes in Amsterdam, or the Bristol or Lewes Pound in the UK (bristolpound.org and www.thelewespound.org). Since 2013, the Cyclos software developed by the STRO (Social Trade Organization) has been available to support communities to develop their own currency at both a local and larger scale (see www.cyclos.org/banks).

\section{Hybrid Transactions}

But no matter how charming the colourful collection of possibilities such as bartering, time banks, and community currencies may be, it is usually limited to a charming neighbourhood or regional initiative for and by a relatively small group of people. The dominant economy, meanwhile, remains shaped by money and organizations. Virtually everything we do (or cannot do) depends on whether we have money. Not having much money results in exclusion from economic and social interaction. Both alarming levels of household debt and energy poverty still remain a reality for too many people.

At the same time, we want society to pay more attention to sustainabilityto a circular economy. Yet, sustainability, circularity, and inclusivity seem to be three ideals that are challenging to link. However, what if we connect and operationalize these ideals through the idea of Inclusive or Social Banking? This form of banking is based on a transaction system in which people pay with hybrid transactions, with which they create their own (local) economy (Fig. 12.3).

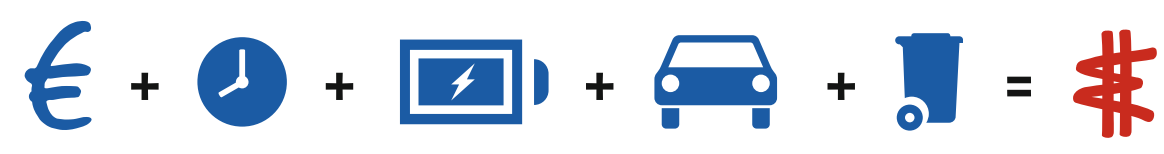

Fig. 12.3 Hybrid transactions 


\section{Definition}

A hybrid transaction system can be defined as a platform in which transactions are in principle not based on monetized assets, but on, for example, time, points, mobility or energy. People can determine the value of their assets peer to peer (sometimes also called the process of P2P valuing) and use them in a transaction that they can design and execute themselves. It is an alternative to the traditional money system, which is based exclusively on monetary transactions between parties.

The idea of hybrid transactions is that other types of value besides money (time, waste, an unused car etc.) can be used and exchanged. This means that people who have enough money can use their time, assets, or skills in exchange for assets that they need. This can enable the inclusion of groups of society that are otherwise excluded from doing transactions.

Using a hybrid transaction system can also lead to a better use of assets, because these assets are not sitting idle or under-utilized. Making use of someone's unused car in exchange for apples from your apple tree leads to more efficient use of existing assets and less waste of perishable products. Furthermore, when you can create more transparency of the assets available in a community, there is less need to buy a product for yourself (think about standing tables for parties, electric screwdrivers, or a book that you can rent, swap or exchange with your neighbour).

This will ultimately mean we can produce fewer things, leading to a positive impact on environmental sustainability and resource use. Thinking about hybrid transactions also leads to interesting new business models, for example local PAAS platforms, selling the use of the product instead of the ownership (functional economy), or local entrepreneurs who can exchange their knowledge and services (cooperative and sharing economy).

All in all, a better allocation of assets, skills, and knowledge by hybrid transactions leads to a more circular and inclusive community. Of course, the question remains of whether and how to implement such a system. For that reason, experiments involving setting up a system around moneyless transactions can be conducted. To better understand how this could work, the following links are to various sources such as a book and two YouTube videos explaining the concept: bit.ly/2J5ZpMe; bit.ly/2VnBDID; bit.ly/2GGsie9. The overall argument/idea is that hybridizing our transactions is possible and can contribute to the development of a resilient sharing and platform economy based on the principles of the commons. What the exact possibilities are and what impact can be achieved through hybrid transaction systems needs to be further demonstrated in practice. 


\subsection{What Is the Business Case of Your Business Model?}

In addition to the concepts of business models, revenue models, and transaction types, another key term you are likely to encounter is business case. It is also common for these terms business models, revenue models, transactions, and business cases to be lumped under one umbrella, which can become somewhat confusing. A business case is commonly defined as a financial model demonstrating that a business model is financially viable without additional external funds such as sponsorship, grants, or subsidies. This infers that actually, everything that really matters in a business model can be translated into money, and other forms of value(s) do not count.

The BMT has a different approach. For a sustainable business model, a conclusive business case means that the nature of the transactions is related to the intended impact. It is possible to conceive of business cases based on social considerations that are not financially viable. Such business cases and the associated business models may continue to depend on external support (such as subsidies) to realize social impact. Here you can easily conclude that some business models and their transactions do not generate money, but that they have a right to exist due to their demonstrable social value. This implies that transactions can lead to multiple values-financial outputs being one of them-but also to a broader range of values, such as a liveable environment, mobility, and food.

\section{Important}

Instock Market

In the Netherlands, some 2.5 million tons of food are wasted every year throughout the entire food chain. As a result, all agricultural land, water, energy, and $\mathrm{CO}_{2}$ emissions for production are lost. This has a huge impact on our earth. It's time for change! The United Nations' Sustainable Development Goals have a clear target: halve food waste by 2030 . To achieve this, many solutions are needed. One is to facilitate chefs in the catering industry to be able to choose products that would otherwise go to waste (www.instoc kmarket.nl). 


\section{How Do You Shape Transactions in Your Business Model, and What Do You Exchange?}

What type of transaction model will you be using within your business model, and why do you make that choice? Is it all about money, or have you developed a model that also includes other values? Sometimes a business model based on money is not workable, while another transaction model offers a solution. Is it possible, for example, to provide part of the funding (per transaction) and financing (long-term investments) with the help of a time bank, energy exchange, waste collection, or the shared use of resources? These are intentionally provocative and challenging questions. After all, our default is to express our transactions in cash almost automatically because it is convenient, but there are other possibilities...

It is also important to reflect on how the type of transactions you deploy will shape your intended impact: can you change the nature of the transactions within your business model in order to stimulate and valorize the impact you want to create? And what additional values and appropriate transactions do you still need to develop your business model further? This approach gives direct insight into how value is added to your business model, using the impact that you will bring about. For example, is it possible to execute part of your activities by exchanging generated electricity for something else? Of course, you need to work out what transactions will look like in such a case, and what technology (maybe blockchain) could support your business model.

\subsection{Case Studies: Value(s) Creation}

\section{Case Study: Bus tickets or food in exchange for waste-Curitiba (Brazil)}

In 1991 the Brazilian city of Curitiba did not have sufficient budget to build a recycling plant, so the local government thought of a way to change the situation. They launched two programmes: (1) Waste that is not waste and (2) Green exchange. The city created a local currency to reward citizens for separating organic and non-organic waste and taking it to the waste stations. In exchange for this service, citizens received an amount of local currency that could be used to buy bus tickets, food, and educational books. The impact on the city was no litter, access to education, and public transport for poor families, which, in turn, created new employment options. The programme resulted in a higher employment level, a cleaner city, a guarantee of food, and social inclusion. https://wwf.panda.org/wwf_news/?204414 


\section{Case Study: Bus tickets in exchange for plastic bottles-Surabaya (Indonesia)}

In the city of Surabaya in Indonesia, the government has initiated a programme to recycle plastic bottles and increase public awareness. A one-hour bus ride costs three large bottles or ten plastic cups. More than 15,000 passengers are currently using this initiative. They travel for free every week in exchange for collecting plastic and enabling its recycling. www.phys.org/news/2019-08-trashtickets-indonesia-plastic-bus.html.

\section{Case Study: Exchanging waste for 15 minutes of WiFi connection-Thinkscream (India)}

The Thinkscream company created a solution to the waste and internet connectivity problem in India. The smart waste bin provides a WiFi connection in exchange for waste. The moment waste is thrown in the waste bin, a sensor activates the WiFi router. The waste bin offers a code for users to log into the WiFi network. In exchange for waste, users can then use the WiFi connection for 15 minutes. www.youtube.com/watch?v=Jd-54aB5B3M.

\section{Case Study: Exchanging waste for food-Mexico City (Mexico)}

A new trade market in Mexico City is helping residents exchange their waste for food vouchers to combat the growing waste problem in the city. The local government subsidizes the local farmers who sell the food and sells the collected waste to recycling plants. In this way, the government hopes to change the population's behaviour and raise awareness of waste recycling. https://edition.cnn.com/2012/06/19/world/americas/mexico-city-barterscheme/index.html.

\section{Case Study: Plastic bottles in exchange for a bus or metro fare-Atac (Italia)}

In Rome, travellers can recycle plastic bottles in exchange for a metro fare. Each bottle has a trade-in value of five cents. By putting it in a deposit machine, they get a discount on a metro ticket. To obtain a free metro ticket of $€ 1.50$, they have to deposit 30 bottles. www.reuters.com/article/us-italy-pollution-pla stic/rome-offers-free-metro-travel-for-plastic-recyclers-idUSKBN1WG3BZ. 


\section{Case Study: Exchanging plastic bottles for public transport fares-Incom (China and Norway)}

Incom is a Sino-Norwegian partnership that was initiated to promote RVMs and waste recycling solutions. The exchange device scans the barcode of the packaging, identifying the material and weight. The machines are installed in Beijing at such places as public transport locations, supermarkets, and schools, where in exchange for recycled goods, people can earn money to use on public transport in China. www.en.incomrecycle.com.

\subsection{Conclusion}

If this chapter shows-and teaches us-anything, it is how difficult it is to make multiple value creation concrete. We shape our society based on a never-ending stream of transactions-large and small, day in and day out. We go to the bakery, buy bread, sell a car or a house-some with short-term impact, others with far-reaching consequences, both negative and positive. The nature of these transactions reveals the values we consider important.

Over the past two centuries, we have increasingly left the organization of value creation to companies. Over the years, companies have focused almost exclusively on money as the central and only medium of exchange. In the resulting business models, many costs and revenues (ecological, social, etc.) are excluded. This has created a very lean, rather shabby transaction model based on monetizing. Anything that cannot be converted into euros does not count and is therefore not counted. We need to change this.

The transition requires a generation of both new business models and underlying transaction models. We therefore need hybrid transaction models that allow for multiple forms of value creation. Using the dominant medium of exchange unknowingly, and maybe even unwillingly, creates path dependency. As long as money is the dominant medium of exchange, we will lapse into existing monetized routines and behaviour. The goal of sustainable business models is not to generate classic profit, but above all, to create a world that makes sense and has value: a world based on what we call collective and shared values where multiple value(s) creation is pursued. 


\section{References}

Buchanan, J. M., \& Stubblebine, W. C. (1962). Externality. Economica, 29(116), 371-384. https://doi.org/10.2307/2551386.

Tukker, A. (2004). Eight types of product-service system: Eight ways to sustainability? Experiences from SusProNet. Business Strategy and the Environment, 13(4), 246-260. https://doi.org/10.1002/bse.414.

Open Access This chapter is licensed under the terms of the Creative Commons Attribution 4.0 International License (http://creativecommons.org/licenses/by/4.0/), which permits use, sharing, adaptation, distribution and reproduction in any medium or format, as long as you give appropriate credit to the original author(s) and the source, provide a link to the Creative Commons license and indicate if changes were made.

The images or other third party material in this chapter are included in the chapter's Creative Commons license, unless indicated otherwise in a credit line to the material. If material is not included in the chapter's Creative Commons license and your intended use is not permitted by statutory regulation or exceeds the permitted use, you will need to obtain permission directly from the copyright holder.

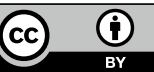

